Research Article

\title{
Energy Analysis and Performance Evaluation of the Adsorption Refrigeration System
}

\author{
H. Z. Hassan \\ Department of Mechanical Engineering, College of Engineering, Alfaisal University, Takhassusi Street, P.O. Box 50927, \\ Riyadh 11533, Saudi Arabia \\ Correspondence should be addressed to H. Z. Hassan; hzahmed@alfaisal.edu
}

Received 13 November 2012; Accepted 29 November 2012

Academic Editors: W. Dai and A. Z. Sahin

Copyright (c) 2013 H. Z. Hassan. This is an open access article distributed under the Creative Commons Attribution License, which permits unrestricted use, distribution, and reproduction in any medium, provided the original work is properly cited.

A complete steady state thermodynamic differential analysis is developed for the adsorption-based refrigeration systems. The introduced thermodynamic model accurately represents the behaviour of adsorption cooling systems, based on a precise, reasonable, and clear fundamental approach. Based on the energy conservation principle, all components and processes in the system are analyzed. The dynamics of adsorption is expressed by the Dubinin-Astakhov adsorption equilibrium model. All types of energy interactions are evaluated in order to determine the theoretical performance and the operating parameters of the system. Moreover, the actual thermodynamic properties of the refrigerant are considered in developing the model. The case studied is an ice maker which uses activated carbon-methanol as the working pair.

\section{Introduction}

The traditional vapor compression refrigeration (VCR) machines are dominating electricity consumers and their operation causes high electricity peak loads [1]. Providing cooling by using a low quality source of energy is a key solution to reduce electrical energy consumption. Low quality energy sources are those sources with low temperature and include solar thermal energy, geothermal energy, and waste heat. Recently, thermally driven cold production (TDCP) systems attract many researchers [2]. The booming progress in the TDCP technology offers a considerable number of systems as alternatives to the VCR machines. These systems include adsorption, absorption, and ejector systems. An advantage of the TDCP systems is the environmentally benign and natural refrigerants which have zero ozone depleting as well as zero global warming potentials. Moreover, the low heat source driving temperature and its wide range make TDCP systems more attractive.

Adsorption cold production (ACP) systems can be powered by heat sources with temperature which is nearenvironmental temperatures and as low as $50^{\circ} \mathrm{C}$, depending on the adsorbent-refrigerant working pair [3]. Moreover, $\mathrm{ACP}$ machines are suitable for working in hot and dry areas because they do not require any extra cooling equipment for high ambient temperatures. Due to the fact that ACP systems use solid absorbent, they are suitable for conditions with serious vibration, such as in fishing boats and locomotives. The most widely used working pairs are activated carbonmethanol [4, 5], activated carbon fibers-methanol [6], activated carbon-ethanol [7], activated carbon-ammonia [8], silica gel-water [9], and zeolite-water [10]. Many researchers have been interested with the study of the ACP system both numerically and experimentally $[3,11,12]$. Moreover, the literature is abundant with numerical studies accomplished on different adsorbent-adsorbate pairs, various ACP system designs, and different system configurations [13-17].

Most of the published studies on the ACP systems were dynamic models to simulate the system and to study its performance $[4,8,18-21]$. Although it is an interesting point to investigate the dynamic behaviour of the ACP system, it is most important to understand its theoretical steady state behaviour and characteristics. However, an obvious and detailed information on the fundamental thermodynamic analysis of the ACP system is limited. Moreover, the introduced work in $[22,23]$ proposed many assumptions and simplifications to the analysis, without enough reasons and accuracy. Although some of the assumptions in $[24,25]$ can 


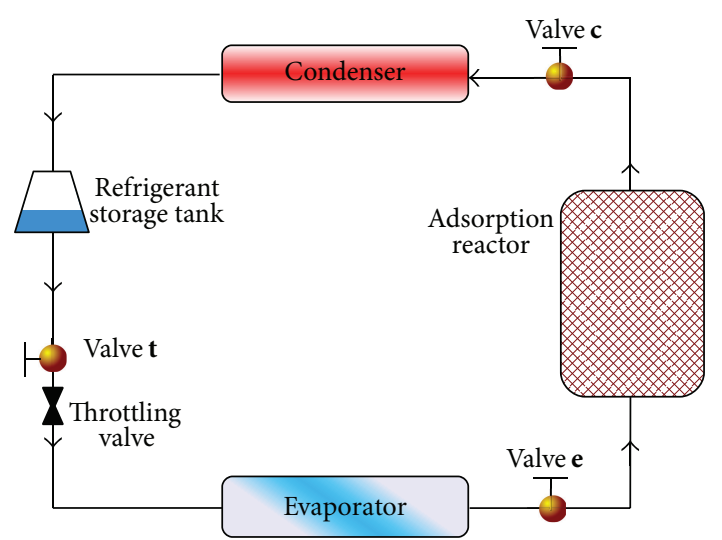

FIgURE 1: Schematic diagram of the ACP system.

be accepted to some extent, other assumptions appear to be far from the reality of the system behaviour. Although Teng et al. [26] and more recently Hassan et al. [27] presented much more better thermodynamic models, they used an integral analysis which cannot provide precise details for the system behaviour.

It is difficult to find any work in the literature which accurately study the steady state thermodynamic behaviour of the ACP system, based on a precise, reasonable, and clear fundamental analysis. Therefore, the major motivation behind the current study is to introduce a complete differential thermodynamic analysis of the ACP system.

\section{Thermodynamic Cycle of the ACP System}

The ACP system is similar to the basic VCR machine except that the power compressor is replaced with a thermally driven compressor which is the adsorption bed. The main components of the basic system are shown in Figure 1. The system consists of an adsorption reactor, a condenser, an evaporator, a refrigerant storage tank, 3 one-way control valves, and a throttling device. The adsorption bed is composed of a type of solid medium that has affinity to physically adsorb and desorb the refrigerant vapor. The basic adsorption refrigeration thermodynamic cycle is illustrated on the conceptual Clapeyron diagram, Figure 2, and its operation time schedule is represented in Figure 3.

Since refrigerant phase change is monovariant, its equilibrium state is defined only by one variable, either by the pressure or the temperature. The dynamic equilibrium condition of the refrigerant is represented by the line on the left in Figure 2. The condition of the gas-solid adsorption equilibrium in the reactor is bivariant and requires two variables to be specified, the concentration ratio and either the temperature or the pressure. Therefore, the temperaturepressure dynamic equilibrium of the gas-solid reactor is represented in Clapeyron diagram by the line in the middle for high concentration and the line in the right for the lower concentration ratios. The working region of the adsorption reactor spans from the lower concentration adsorption equilibrium line to the higher concentration adsorption equilibrium line. The adsorbent-adsorbate reactor cycle consists mainly of four processes; pressurization and preheating process at the constant higher concentration (isosteric heating process $1 \rightarrow 2$ ), desorption-condensation process at constant condenser pressure (isobaric heating process $2 \rightarrow$ 3 ), depressurization and precooling process at the constant lower concentration (isosteric cooling process $3 \rightarrow 4$ ), and adsorption-evaporation process at constant evaporator pressure (isobaric cooling process $4 \rightarrow 1$ ) $[1,4]$.

At the beginning of the cycle, state $\mathbf{1}$, the reactor is isolated from both the condenser and the evaporator by valves $\mathbf{c}$ and $\mathbf{e}$ and is completely charged and saturated with the refrigerant. The pressure inside the reactor initially equals the evaporator pressure $P_{\mathrm{ev}}$ and its temperature is uniform and equals the ambient temperature $T_{\mathrm{amb}}$, state 1 . When the reactor is heated, both pressure and temperature inside the adsorption bed are elevated. This constant concentration heating phase continues till state 2 where the pressure reaches a value that equals the condenser pressure $P_{\text {con }}$. At state 2 , valve $\mathbf{c}$ opens and the refrigerant vapor starts to desorb from the bed and flows towards the condenser. In parallel with the desorption process, the adsorption reactor is still being heated and the pressure inside the bed is fixed at the condenser pressure. The temperature continues to increase above the generation temperature $T_{\text {gen }}$. The refrigerant content inside the reactor continues to decrease as more adsorbate is being freed from the reactor. In the condenser, the refrigerant vapor losses both sensible heat and latent heat and condenses at the preset condensation temperature $T_{\text {con }}$ corresponding to the condenser pressure $P_{\text {con }}$. The condensed refrigerant is then collected and stored in the refrigerant storage tank, Figure 1. It is worth noting that process $1 \rightarrow 2 \rightarrow 3$ is equivalent to the compression process in case of the VCR system. The desorption process continues while the bed is being heated and its temperature is continuously increasing whereas the pressure keeps its value at the constant condenser pressure. This operation continues for a certain period of time until one of the following stopping criteria is reached.

(1) The temperature of the adsorption bed reaches the maximum allowable value at which the refrigerant becomes chemically unstable.

(2) The reactor temperature reaches the heat source temperature and no more adsorbate can be generated from the bed.

Whichever stopping condition is approached, valve c is closed in order to disconnect the adsorption bed from the condenser and start the bed cooling process, $3 \rightarrow 4$. The reactor cooling process takes place at the constant low concentration and both of the temperature and pressure decrease, till its pressure reaches the evaporator pressure $P_{\mathrm{ev}}$ at state $\mathbf{4}$ on Clapeyron diagram, Figure 2. At state 4, valve $\mathbf{t}$ is opened to allow the liquid refrigerant, which is previously stored in the storage tank, to pass through the expansion device. Due to the throttling process, the liquid refrigerant is self-cooled by evaporating some liquid before it enters the evaporator. At the same instant of opening 


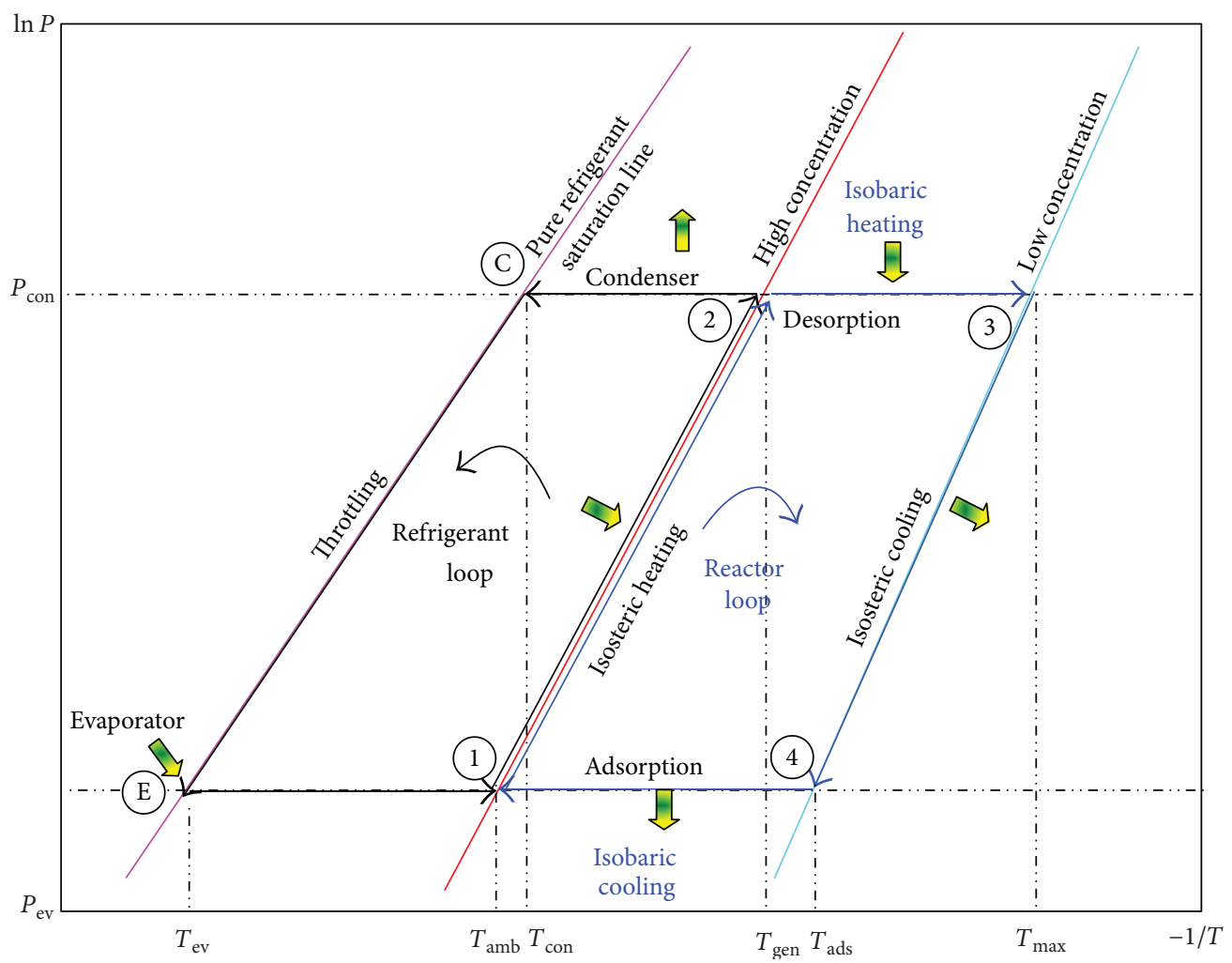

FIgURE 2: Clapeyron diagram for the basic ACP thermodynamic cycle, [1].

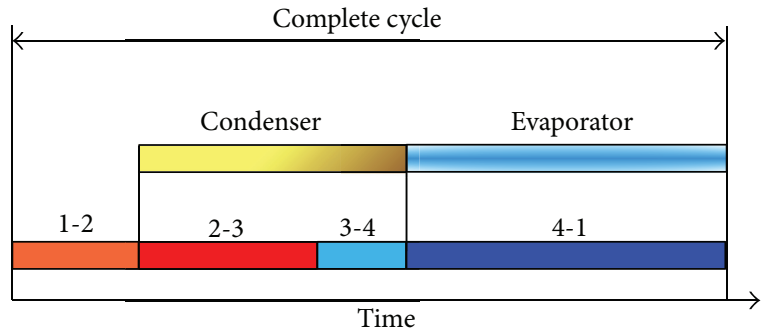

Figure 3: Operation time schedule of the basic ACP system.

valve $\mathbf{t}$, valve e opens and the refrigerant vapor from the evaporator flows towards the reactor. This process consists of the refrigerant adsorption within the reactor in parallel with the production of cooling effect inside the evaporator. The reactor is being cooled during this period in order to remove the generated heat from the exothermic adsorption process. The evaporation-adsorption process takes place at the constant evaporator pressure and continues till the adsorption bed retains its higher cycle isostere, at point $\mathbf{1}$.

\section{Definitions and Terminologies}

The solid adsorbent is a type of porous media that has cavities, channels, or interstices, which are deeper than being wide. The large surface area of the adsorption media is mainly

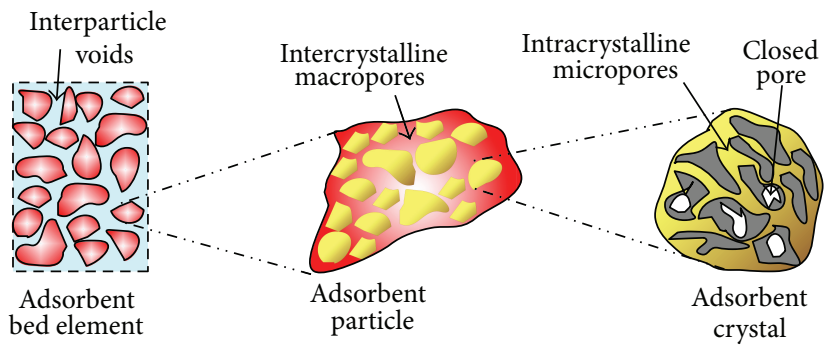

Figure 4: Schematic diagram illustrating void spaces within the adsorbent material.

due to the micropore and mesopore internal structure. Porous materials may be one of two types: agglomerates or aggregates. Agglomerates are rigid and consolidated porous material which consists of the assemblage of macroscopic particles whose dimensions exceed those of the pores by many orders of magnitude, like silica gel. Aggregates are loose and unconsolidated assemblage of individual particles, like powders, $[28,29]$.

As illustrated in Figure 4, the total void space, $V_{\text {viod }}$, within an element of the adsorbent consists of three components: the interparticle voids, the open pore voids, and the closed pore voids. The open pore type of void spaces is due to the contribution of both the intercrystalline macropores and the intracrystalline micropores void spaces as well as the 
mesopore spaces. The total porosity of any porous material is defined as the ratio between the total void spaces within the solid porous material and the material bulk volume. The bulk volume of a material includes the contribution of skeletal volume, pore void volume, and interparticle space volume [30]. Therefore, an adsorption bed with a bulk volume of $V_{b}$ has its total porosity, $\varepsilon$, calculated from

$$
\varepsilon=\varepsilon_{p}+\left(1-\varepsilon_{p}\right) \varepsilon_{b},
$$

where $\varepsilon_{b}$ is the packed bed porosity which represents the interparticle void spaces within the bed per unit bulk volume of the bed. The particle porosity, $\varepsilon_{p}$, is the the total pore volume, open and closed, per unit bulk volume of the particle and is given in terms of the particle density, $\rho_{p}$, and true density, $\rho_{s}$, as follows;

$$
\varepsilon_{p}=1-\frac{\rho_{p}}{\rho_{s}} .
$$

The true density (also, absolute density, helium density, or skeletal density) of the material is calculated by excluding all pores (open and closed) and interparticle voids. Therefore it is comparable to the theoretical density of this type of solid in the absence of pores, whereas, particle density (also apparent or mercury density) is the density of the material including all pore system, open and closed pores. If both apparent and real densities are known, the difference of their inverses will provide the total pore volume per unit mass of the material. A third type of density of porous media is the bulk density. The bulk density includes all the pore system as well as interparticle voids between loose particles [28-30].

An important parameter in dealing with adsorption in porous media is the adsorbed phase volume fraction, $\theta$. The adsorbed phase volume fraction is defined as the volume of the adsorbate phase, $V_{a}$, per unit bulk volume of the adsorption bed, $V_{b}$ :

$$
\theta=\frac{V_{a}}{V_{b}} .
$$

Therefore, the mass of the solid media, $m_{\mathrm{sm}}$, the mass of gas phase, $m_{g}$, and the mass of the adsorbate phase, $m_{a}$, can be expressed in terms of the total bed porosity, $\varepsilon$, and the adsorbate volume fraction, $\theta$, as follows:

$$
\begin{gathered}
m_{\mathrm{sm}}=\rho_{s}[1-\varepsilon] V_{b}, \\
m_{g}=\rho_{g}(P, T)[\varepsilon-\theta] V_{b}, \\
m_{a}=\rho_{a}(T) \theta V_{b},
\end{gathered}
$$

where $\rho_{g}(P, T)$ is the density of the gas phase at the temperature and pressure of the adsorption reactor. The density of the adsorbate phase, $\rho_{a}(T)$, is considered equal to the density of the liquid refrigerant at the temperature of the bed.

Another important parameter is the adsorbate concentration ratio $\mathscr{X}$ which is the mass of the adsorbate phase per unit

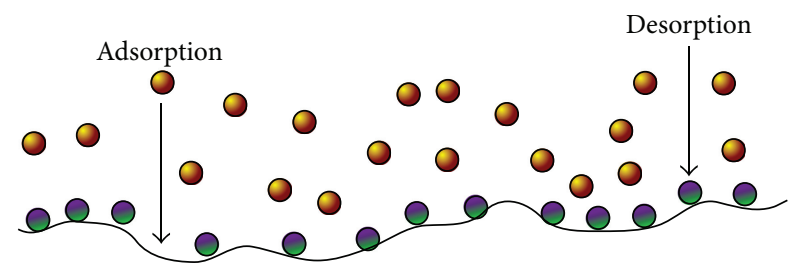

Gas phase

Adsorbed phase

FIGURE 5: Adsorption equilibrium dynamics.

mass of the solid adsorbent porous media. From (4), we can express $\mathscr{X}$ as follows:

$$
\mathscr{X}=\frac{m_{a}}{m_{\mathrm{sm}}}=\frac{\rho_{a}(T)}{\rho_{s}} \frac{\theta}{1-\varepsilon} .
$$

\section{The Adsorption Equilibrium Model}

The adsorption characteristics of a certain pair depend on the nature of the adsorbate, the nature of the adsorbent, the reactivity of the surface, the surface area, and the temperature and the pressure at which adsorption process takes place. When a solid surface is exposed to a gas, the molecules of the gas strike the surface of the solid. Some of the striking molecules attach and stick to the solid surface and as a consequence become adsorbed, while others rebound back. The rate of adsorption is large at the beginning of the process because the whole surface is uncovered. The adsorption rate continues to decrease since more and more of the solid surface is being covered by the adsorbate phase molecules. Meanwhile, the rate of desorption increases due to the escaping of the gas molecules from the covered surface, Figure 5. An equilibrium is approached when the rate of adsorption is equal to the rate of desorption. At this point of time, the gas-solid system is said to be in adsorption dynamic equilibrium because the number of molecules sticking to the surface is equal to the number of molecules rebounding from the surface [31].

The amount of adsorbate phase per unit mass of the solid adsorbent at the equilibrium condition is known as the adsorbate equilibrium concentration ratio and is denoted by $\mathscr{X}^{*}$. It is noteworthy that the adsorbent concentration ratio for a certain adsorption pair at the equilibrium is a bivariant property which depends upon the pressure of the gas as well as the temperature at which the adsorption process takes place, that is $\mathscr{X}^{*}=f(P, T)$. The adsorption equilibrium theories are widely introduced in the literature [31-33]. One of the mostly used adsorption equilibrium models is the Dubinin-Astakhov (D-A) model [34-36]. The D-A equation has been developed mainly to describe the adsorption of gases by microporus adsorbents especially in case of activated carbon and is better than other models due to its thermodynamic character. According to Dubinin-Astakhov model, the adsorbate concentration ratio at equilibrium $\mathscr{X}^{*}$ is related 
to the adsorption process pressure and temperature by the following equation:

$$
\mathscr{X}^{*}=\rho_{a}(T) W_{o} \operatorname{Exp}\left[-D\left(T \ln \left[\frac{P_{s}(T)}{P}\right]\right)^{n}\right],
$$

where $W_{o}$ is the maximum adsorption capacity, $D$ and $n$ are constants which depend on the adsorbate-adsorbent pair, and $\rho_{a}(T)$ and $P_{s}(T)$ are the adsorbate density and the saturation pressure corresponding to the bed temperature.

Equation (6) can be rearranged in order to give the pressure $P$ in an explicit formula. After doing this arrangement,

$$
P=P_{s}(T) \operatorname{Exp}\left\{\frac{-1}{T}\left[\frac{1}{D} \ln \left(\frac{\rho_{a}(T) W_{o}}{\mathscr{X}^{*}}\right)\right]^{1 / n}\right\} .
$$

Also, the adsorbate volume fraction at the equilibrium condition, $\theta^{*}$, is found from the following relation:

$$
\theta^{*}=\mathscr{X}^{*}(1-\varepsilon) \frac{\rho_{s}}{\rho_{a}(T)} .
$$

\section{Isosteric Heat of Adsorption and Desorption}

When the gas or the vapor is physically adsorbed in the adsorbent solid media, two types of thermal energy are liberated: the latent heat of the evaporation of the adsorbed liquid and the additional heat of wetting which is due to the electrostatic forces involved in the physical adsorption process. The combined latent heat and the heat of wetting are transformed into sensible heat and dissipated into the adsorbent causing an increase in its temperature [37]. Therefore, the process of adsorption is exothermic whereas the process of desorption is endothermic. From the thermodynamics point of view, the adsorption process of a gas or a vapor on a solid adsorbent is a spontaneous process during which the free energy of the system decreases. Moreover, when the gas molecules are adsorbed, the system entropy is decreased since the thermodynamic probability of identifying the microscopic state increases. Therefore, it can be shown that the heat of adsorption should be negative and therefore the process is exothermic.

The amount of heat required to adsorb or desorb a unit mass of the adsorbate is known as the isosteric heat of adsorption or desorption, respectively. It has been common in the literature to use the Clapeyron-Clausius equation to calculate the heat of adsorption. Despite the simplicity of Clapeyron-Clausius equation, it is applicable only for the ideal gases $[38,39]$. In the present analysis, the more general Clapeyron equation is used to determine the heat of adsorption or desorption. This isosteric heat per unit mass of adsorbate, $q_{\text {sh }}$, is calculated from the Clapeyron equation:

$$
q_{\mathrm{sh}}=T\left(\frac{1}{\rho_{g}(P, T)}-\frac{1}{\rho_{a}(T)}\right)\left[\frac{\partial P}{\partial T}\right]_{X^{*}=\mathrm{con}} .
$$

By performing a partial differentiation for the pressure equation, (7), with respect to the temperature and substituting it to (9), a formula for the adsorption heat can be obtained in terms of pressure and temperature as follows:

$$
\begin{aligned}
q_{\mathrm{sh}}= & T\left(\frac{1}{\rho_{g}(P, T)}-\frac{1}{\rho_{a}(T)}\right) \\
\times & \left\{\frac{P}{P_{s}(T)} \frac{d}{d T}\left[P_{s}(T)\right]-\frac{P}{n D T \rho_{a}(T)} \cdot\left[T \ln \left(\frac{P_{s}(T)}{P}\right)\right]^{1-n}\right. \\
& \left.\cdot \frac{d}{d T}\left[\rho_{a}(T)\right]+\frac{P}{T} \ln \left[\frac{P_{s}(T)}{P}\right]\right\} .
\end{aligned}
$$

It is noteworthy that the difference between the gas phase and the adsorbate phase specific enthalpies is equal to the adsorption isosteric heat. Thus, the specific enthalpy of the adsorbed refrigerant can be found from the following equation:

$$
h_{a}(P, T)=h_{g}(P, T)-q_{\text {sh }} .
$$

Moreover, the specific internal energy of the adsorbed phase is expressed by

$$
u_{a}(P, T)=h_{a}(P, T)-\frac{P}{\rho_{a}(T)} .
$$

\section{First Law Analysis of the ACP System}

In this section, the mathematical model representing the ACP system operation is developed. This model is based on a steady state first law differential analysis in order to calculate all types of energy interactions which take place in all of the system components and all of the processes of the theoretical cycle. The derivation of the mathematical model is based on the actual thermodynamic properties of the refrigerant rather than considering it to behave like a perfect gas in the vapor phase. Therefore, either the refrigerant equation of state or the tabulated thermodynamic properties could be used in the numerical solution of the model. In the following subsections, the four process in the theoretical ACP cycle are analyzed first. Following that, the condenser, the throttling device, and the evaporator are analyzed.

6.1. Process $1 \rightarrow 2$. In this process, the adsorption bed is preheated at the constant highest isostere line, $\mathscr{X}_{\max }^{*}$. For a given evaporator temperature, $T_{\text {ev }}$, the corresponding evaporator pressure, $P_{\mathrm{ev}}$, is the saturation pressure of the refrigerant vapor corresponding to $T_{\mathrm{ev}}$. Furthermore, the maximum adsorbate concentration ratio $\mathscr{X}_{\max }^{*}$ is determined from (6) corresponding to the evaporator pressure $P_{\mathrm{ev}}$ and the ambient temperature $T_{\mathrm{amb}}$. The relation between the pressure and temperature along the path $1 \rightarrow 2$ is found from (7) at the constant concentration ratio which equals $\mathscr{X}_{\max }^{*}$. Furthermore, the variation of the adsorbate volume fraction, $\theta^{*}$, along the highest concentration path can be determined from (8). 


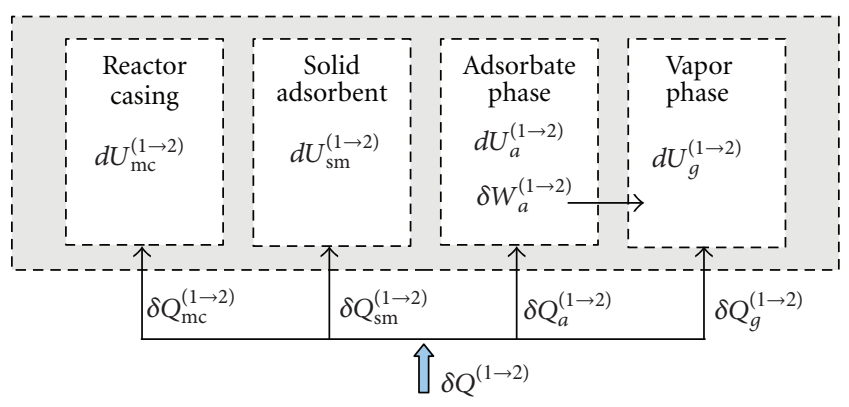

FIgURE 6: Energy flow diagram for the adsorption reactor during process $1 \rightarrow 2$.

During the present process, there is no desorption taking place and therefore, the mass of the gas phase $m_{g}$ as well as the mass of the adsorbate phase $m_{a}$ remains constant through the process path $1 \rightarrow 2$. The added energy during this process causes sensible heating of the adsorption bed constituents. A differential amount of energy, $\delta Q^{(1 \rightarrow 2)}$, which is introduced to the adsorption reactor, causes a step change in the adsorption bed state. This infinitesimal added energy can be represented as illustrated in Figure 6 and is given by

$$
\delta Q^{(1 \rightarrow 2)}=\delta Q_{\mathrm{mc}}^{(1 \rightarrow 2)}+\delta Q_{\mathrm{sm}}^{(1 \rightarrow 2)}+\delta Q_{a}^{(1 \rightarrow 2)}+\delta Q_{g}^{(1 \rightarrow 2)},
$$

where $\delta \mathrm{Q}_{\mathrm{mc}}^{(1 \rightarrow 2)}, \delta \mathrm{Q}_{\mathrm{sm}}^{(1 \rightarrow 2)}, \delta \mathrm{Q}_{a}^{(1 \rightarrow 2)}$, and $\delta \mathrm{Q}_{g}^{(1 \rightarrow 2)}$ are the differential sensible energies absorbed by the adsorption reactor metallic shell, the porous adsorbent media, the adsorbate phase, and the refrigerant vapor phase, respectively, as seen in Figure 6.

The energy absorbed by the metallic cover of the adsorption bed causes a step temperature rise of $d T$ and is given by

$$
\delta Q_{\mathrm{mc}}^{(1 \rightarrow 2)}=m_{\mathrm{mc}} C_{\mathrm{mc}} d T .
$$

Also, The thermal energy consumed in sensible heating of the adsorption bed porous media is calculated from

$$
\delta Q_{\mathrm{sm}}^{(1 \rightarrow 2)}=m_{\mathrm{sm}} C_{\mathrm{sm}} d T .
$$

The energy required by the adsorbate phase in order to cause an infinitesimal step change of its state is divided in two parts which has two contributions, as illustrated in Figure 6. The first contribution appears in the increase of the adsorbate internal energy. The second part of the energy absorbed by the adsorbate phase contributes in moving the boundary between the gas and the adsorbate phases and causes compression or expansion for the adsorbate phase. Therefore, the differential amount of energy input to the adsorbate phase can be expressed as follows:

$$
\delta Q_{a}^{(1 \rightarrow 2)}=\delta W_{a}+m_{a}^{(1 \rightarrow 2)} d u_{a},
$$

where $\delta W_{a}$ is given as

$$
\delta W_{a}=V_{b} P d \theta^{*} .
$$

The adsorbate mass, $m_{a}^{(1 \rightarrow 2)}$, is constant during this process and is given by

$$
m_{a}^{(1 \rightarrow 2)}=m_{\mathrm{sm}} \mathscr{X}_{\max }^{*} .
$$

The thermal energy required by the refrigerant vapor phase is calculated from the following equation

$$
\delta Q_{g}^{(1 \rightarrow 2)}=-\delta W_{a}+m_{g}^{(1 \rightarrow 2)} d u_{g},
$$

where $m_{g}^{(1 \rightarrow 2)}$ is the mass of the vapor phase which is constant during this process and is given by

$$
m_{g}^{(1 \rightarrow 2)}=V_{b} \rho_{g}\left(P_{\mathrm{ev}}, T_{\mathrm{amb}}\right)\left[\varepsilon-\frac{m_{\mathrm{sm}} X_{\mathrm{max}}^{*}}{V_{b} \rho_{a}\left(T_{\mathrm{amb}}\right)}\right] .
$$

6.2. Process $2 \rightarrow 3$. During this process the adsorption reactor acts as a generator and undergoes the desorption phase at the constant condenser pressure. For a given value of the condensation temperature, $T_{\text {con }}$, the condenser pressure is equal to the refrigerant saturation pressure corresponding to $T_{\text {con }}$. Moreover, the adsorbate concentration ratio decreases during this process from its maximum value, $\mathscr{X}_{\max }^{*}$, at state 2 to its minimum value, $X_{\min }^{*}$, at state 3 . Equation (6) is used to describe this variation along the process path $2 \rightarrow 3$ as a function of the temperature and with the pressure value set to $P_{\text {con }}$. Also, the variation of the adsorbate volume fraction, $\theta^{*}$, along path $2 \rightarrow 3$, is calculated from (8).

It is noteworthy that the total energy required to drive this process has two main effects. The first effect causes a sensible heating of all the adsorption bed constituents and a change in their internal energy. The second effect activates the desorption of the refrigerant from the adsorbent media and generates the gas phase. The infinitesimal amount of energy which is required to cause a step change in the system state along the path $2 \rightarrow 3$ can be expressed as follows:

$$
\delta Q^{(2 \rightarrow 3)}=\delta Q_{\mathrm{mc}}^{(2 \rightarrow 3)}+\delta Q_{\mathrm{sm}}^{(2 \rightarrow 3)}+\delta Q_{a}^{(2 \rightarrow 3)}+\delta Q_{g}^{(2 \rightarrow 3)} .
$$

The energies required for sensibly heating the reactor metallic casing and the adsorbent porous solid media are given by the following two equations, respectively:

$$
\begin{aligned}
& \delta Q_{\mathrm{mc}}^{(2 \rightarrow 3)}=m_{\mathrm{mc}} C_{\mathrm{mc}} d T, \\
& \delta Q_{\mathrm{sm}}^{(2 \rightarrow 3)}=m_{\mathrm{sm}} C_{\mathrm{sm}} d T .
\end{aligned}
$$

During this isobaric desorption process, the mass of the adsorbate phase, $m_{a}^{(2 \rightarrow 3)}$, is continuously decreasing since the refrigerant is being freed from the adsorption bed and flows towards the condenser. Hence, the concentration ratio is continuously decreasing along the process path $2 \rightarrow 3$ as well. In this case and according to the conservation of energy principle, the differential amount of energy $\delta Q_{a}^{(2 \rightarrow 3)}$ which is added to the adsorbate phase, as illustrated in Figure 7, is expressed by

$$
\delta Q_{a}^{(2 \rightarrow 3)}=d U_{a}^{(2 \rightarrow 3)}+h_{g}\left(P_{\text {con }}, T\right) \delta m_{\mathrm{des}}+\delta W_{a},
$$




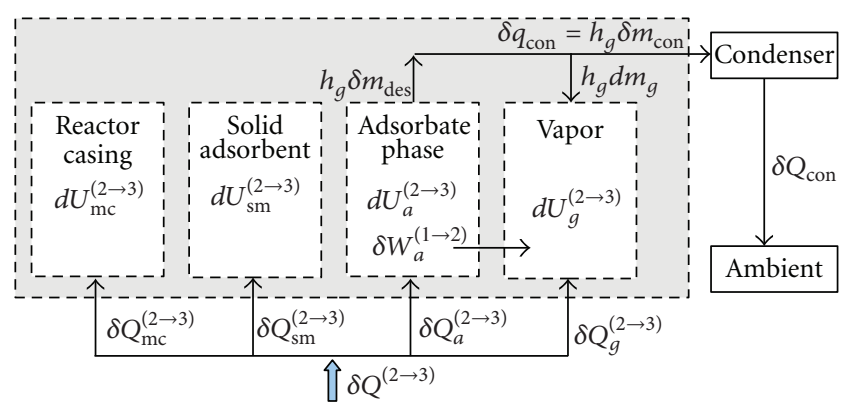

FIGURE 7: Energy flow diagram for the adsorption reactor during process $2 \rightarrow 3$.

where $d U_{a}^{(2 \rightarrow 3)}$ is the step change in the total internal energy of the adsorbate refrigerant phase and is given by

$$
d U_{a}^{(2 \rightarrow 3)}=m_{a}^{(2 \rightarrow 3)} d u_{a}+u_{a} d m_{a},
$$

where $m_{a}^{(2 \rightarrow 3)}$ is the adsorbate phase mass in this process and is given by

$$
\begin{gathered}
m_{a}^{(2 \rightarrow 3)}=m_{\mathrm{sm}} X^{*}, \\
d m_{a}=m_{\mathrm{sm}} d X^{*} .
\end{gathered}
$$

The second term in (23) is the infinitesimal amount of energy which is carried by the desorbed vapor when its phase changes from the adsorbate phase to the gas phase. When a differential mass $\delta m_{\text {des }}$ changes from the adsorbed phase to the gas phase, the corresponding required energy is calculated from

$$
\delta Q_{\mathrm{des}}=\delta m_{\mathrm{des}} q_{\mathrm{sh}} .
$$

The change in the mass of the adsorbate phase is due to the releasing of a differential amount from this mass into the gas phase. Therefore, we can write

$$
\delta m_{\mathrm{des}}=-d m_{a}^{2 \rightarrow 3} .
$$

Regarding the refrigerant vapor phase, its mass $m_{g}^{(2 \rightarrow 3)}$ is varying during the desorption process. By applying the conservation of energy principle on the refrigerant vapor phase, as shown in Figure 7, we get

$$
\delta Q_{g}^{(2 \rightarrow 3)}=d U_{g}^{(2 \rightarrow 3)}-\delta W_{a}^{(2 \rightarrow 3)}-d m_{g}^{(2 \rightarrow 3)} h_{g}\left(P_{\text {con }}, T\right) .
$$

The first term in (28), $d U_{g}^{(2 \rightarrow 3)}$, is the change in the total internal energy of the vapor refrigerant which is calculated from

$$
d U_{g}^{(2 \rightarrow 3)}=m_{g}^{(2 \rightarrow 3)} d u_{g}+u_{g} d m_{g} .
$$

The differential amount of energy which is transported from the adsorption reactor to the condenser is given by

$$
\delta q_{\mathrm{con}}=h_{g}\left(P_{\text {con }}, T\right) \delta m_{\text {con }}
$$

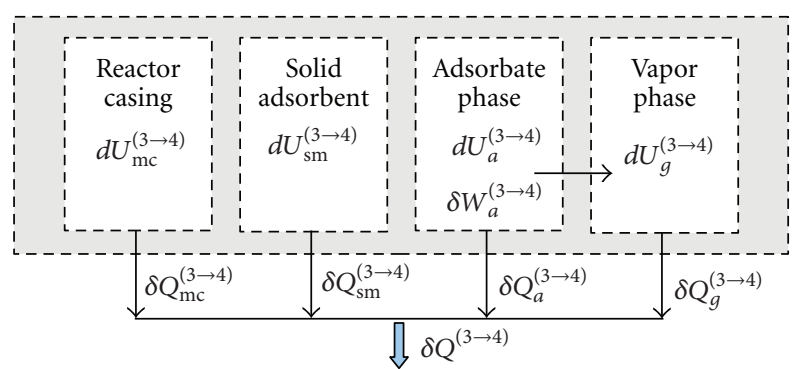

FIGURE 8: Energy flow diagram for the adsorption reactor during process $3 \rightarrow 4$.

where $\delta m_{\text {con }}$ is the differential mass that leaves the adsorption bed and flows towards the condenser. This infinitesimal amount of mass equals the negative change of the total refrigerant mass content inside the adsorption reactor. Mathematically, it can be written as follows:

$$
\delta m_{\text {con }}=-\left(d m_{a}^{2 \rightarrow 3}+d m_{g}^{2 \rightarrow 3}\right) .
$$

6.3. Process $3 \rightarrow 4$. During this cooling process, the adsorbate concentration ratio remains constant at its minimum cyclic value, $X_{\min }^{*}$. The value of $X_{\min }^{*}$ is calculated from (6) corresponding to the condenser pressure, $P_{\text {con }}$, and the highest cycle temperature reached, $T_{\max }$. Additionally, the variation of the reactor pressure with the temperature along the path $3 \rightarrow 4$ is found from (7) at the constant concentration ratio, $X_{\min }^{*}$. Also, the variation of the adsorbate volume fraction, $\theta^{*}$, along this minimum concentration path can be determined from (8).

The energy which is lost from the adsorption bed to the ambient heat sink at $T_{\mathrm{amb}}$ is in a sensible form that results in the reduction of the bed temperature. In this process, there is no adsorption taking place and therefore, the mass of the gas phase as well as the adsorbate phase remains constant through this path.

The differential amount of energy lost from the bed to the ambient surroundings, $\delta Q^{(3 \rightarrow 4)}$, during this stage, as represented in Figure 8, is given by

$$
\delta \mathrm{Q}^{(3 \rightarrow 4)}=\delta \mathrm{Q}_{\mathrm{mc}}^{(3 \rightarrow 4)}+\delta \mathrm{Q}_{\mathrm{sm}}^{(3 \rightarrow 4)}+\delta \mathrm{Q}_{a}^{(3 \rightarrow 4)}+\delta \mathrm{Q}_{\mathrm{g}}^{(3 \rightarrow 4)},
$$

where $\delta Q_{\mathrm{mc}}^{(3 \rightarrow 4)}, \delta Q_{\mathrm{sm}}^{(3 \rightarrow 4)}, \delta Q_{a}^{(3 \rightarrow 4)}$, and $\delta Q_{g}^{(3 \rightarrow 4)}$ are the energies lost from the adsorption bed cover, the porous media, the adsorbate phase, and the gas phase, respectively.

The energy lost from the adsorption bed metallic cover and the adsorption bed solid state are calculated from the following equations:

$$
\begin{aligned}
& \delta Q_{\mathrm{mc}}^{(3 \rightarrow 4)}=-m_{\mathrm{mc}} C_{\mathrm{mc}} d T, \\
& \delta Q_{\mathrm{sm}}^{(3 \rightarrow 4)}=-m_{\mathrm{sm}} C_{\mathrm{sm}} d T .
\end{aligned}
$$

By the same methodology which has been followed in process $1 \rightarrow 2$, the adsorbate phase loss in energy is due to the decrease of the adsorbate internal energy and the amount 
of energy extracted in the expansion or compression of the boundary. As a consequence, the total amount of energy output from the adsorbate refrigerant to cause a step change in its state is express as

$$
\delta Q_{a}^{(3 \rightarrow 4)}=-V_{b} P d \theta^{*}-m_{a}^{(3 \rightarrow 4)} d u_{a},
$$

where $m_{a}^{(3 \rightarrow 4)}$ is the constant adsorbate phase mass in the present process and is calculated from

$$
m_{a}^{(3 \rightarrow 4)}=m_{\mathrm{sm}} \mathscr{X}_{\min }^{*}
$$

Also, the thermal energy losses from the refrigerant vapor phase during the current process are calculated by the following expression:

$$
\delta Q_{g}^{(3 \rightarrow 4)}=V_{b} P d \theta^{*}-m_{g}^{(3 \rightarrow 4)} d u_{g}
$$

where $m_{g}^{(3 \rightarrow 4)}$ is the mass of the gas phase which is determined from the following equation:

$$
m_{g}^{(3 \rightarrow 4)}=V_{b} \rho_{g}\left(P_{\text {con }}, T_{\max }\right)\left[\varepsilon-\frac{m_{\text {sm }} X_{\min }^{*}}{V_{b} \rho_{a}\left(T_{\max }\right)}\right] \text {. }
$$

6.4. Process $4 \rightarrow 1$. In this process, the adsorption bed is being used as an adsorber while it is being cooled at the constant evaporator pressure. The mass of the adsorbate phase inside the reactor $m_{a}^{(4 \rightarrow 1)}$ is continuously increasing as more refrigerant vapor leaves the evaporator and enters the adsorption bed. As a consequence, the concentration ratio increases also during this process from its minimum value $\mathscr{X}_{\min }^{*}$ to its maximum value $\mathscr{X}_{\max }^{*}$. The bed temperature decreases from the adsorption temperature $T_{\text {ads }}$ to the ambient temperature at the end of the process path $4 \rightarrow$ 1. For a given value of $T_{\mathrm{ev}}$ the evaporator pressure equals the refrigerant saturation pressure corresponding to $T_{\mathrm{ev}}$. Equation (6) is used to describe the variation of $\mathscr{X}^{*}$ as a function of the bed temperature and $P_{\mathrm{ev}}$. Also, the variation of $\theta^{*}$ along the path $4 \rightarrow 1$ is calculated from (8).

Energy removed from the bed during the current process consists of the reactor sensible cooling energy in addition to the adsorption energy. As seen in Figure 9, the infinitesimal total amount of energy removed from the reactor to cause a step change in the system state along the path $4 \rightarrow 1$ is given in a differential form as follows:

$$
\delta Q^{(4 \rightarrow 1)}=\delta Q_{\mathrm{mc}}^{(4 \rightarrow 1)}+\delta Q_{\mathrm{sm}}^{(4 \rightarrow 1)}+\delta Q_{a}^{(4 \rightarrow 1)}+\delta Q_{g}^{(4 \rightarrow 1)} .
$$

Energies required for sensibly cooling the bed metallic cover and the adsorbent porous solid media are given by the following two equations, respectively:

$$
\begin{aligned}
& \delta Q_{\mathrm{mc}}^{(4 \rightarrow 1)}=-m_{\mathrm{mc}} C_{\mathrm{mc}} d T, \\
& \delta Q_{\mathrm{sm}}^{(4 \rightarrow 1)}=-m_{\mathrm{sm}} C_{\mathrm{sm}} d T .
\end{aligned}
$$

According to the first law of thermodynamics, the differential amount of energy, $\delta Q_{a}^{(4 \rightarrow 1)}$, which is taken from the refrigerant adsorbate phase in order to cause a step change of its state along the process path is expressed by

$$
\delta Q_{a}^{(4 \rightarrow 1)}=h_{\mathrm{ev}} \delta m_{\mathrm{ads}}-d U_{a}^{(4 \rightarrow 1)}-\delta W_{a}^{(4 \rightarrow 1)},
$$

where $h_{\mathrm{ev}}$ is the refrigerant vapor saturation enthalpy corresponding to the evaporator pressure and $d U_{a}^{(4 \rightarrow 1)}$ is given by

$$
d U_{a}^{(4 \rightarrow 1)}=m_{a}^{(4 \rightarrow 1)} d u_{a}+u_{a} d m_{a} .
$$

The differential mass $\delta m_{\text {ads }}$ which is transformed from the vapor phase to the adsorbate phase is given by

$$
\delta m_{\mathrm{ads}}=d m_{a}^{4 \rightarrow 1} .
$$

The corresponding infinitesimal amount of the adsorption heat $\delta Q_{\text {ads }}$ is calculated from

$$
\delta Q_{\mathrm{ads}}=\delta m_{\mathrm{ads}} q_{\mathrm{sh}} .
$$

The change in the adsorbed mass $d m_{a}^{4 \rightarrow 1}$ is given as a function of the concentration ratio by

$$
d m_{a}^{4 \rightarrow 1}=m_{\mathrm{sm}} d \mathscr{X}^{*} .
$$

Regarding the refrigerant gas phase, from the conservation of energy principle and energy flow diagram which is illustrated in Figure 9 we get

$$
\delta Q_{g}^{(4 \rightarrow 1)}=-d U_{g}^{(4 \rightarrow 1)}+\delta W_{a}^{(4 \rightarrow 1)}+d m_{g} h_{\mathrm{ev}},
$$

where $d U_{g}^{(4 \rightarrow 1)}$ is the change in the total internal energy of the vapor refrigerant and is given by

$$
d U_{g}^{(4 \rightarrow 1)}=m_{g}^{(4 \rightarrow 1)} d u_{g}+u_{g} d m_{g},
$$

where $m_{g}^{(4 \rightarrow 1)}$ is expressed as

$$
m_{g}^{(4 \rightarrow 1)}=V_{b} \rho_{g}\left(P, T_{\mathrm{amb}}\right)\left[\varepsilon-\frac{m_{\mathrm{sm}} \mathscr{X}^{*}}{V_{b} \rho_{a}\left(T_{\mathrm{amb}}\right)}\right] .
$$

The differential mass that leaves the evaporator and enters the adsorption bed, $\delta m_{\mathrm{ev}}$, equals the change of the total refrigerant mass content inside the adsorption reactor. Mathematically, it can be written as follows:

$$
\delta m_{\mathrm{ev}}=d m_{a}^{4 \rightarrow 1}+d m_{g}^{4 \rightarrow 1} .
$$

6.5. The Condenser. The refrigerant vapor enters the condenser as soon as it desorbs from the adsorption bed. In the condenser, the refrigerant gas is being desuperheated first by removing sensible energy from the superheated vapor across a driving temperature difference of $T-T_{\mathrm{amb}}$. When the refrigerant vapor reaches the saturated vapor state, it starts to condense and the latent energy of condensation is rejected to the ambient heat sink across a difference of $T_{\text {con }}-$ $T_{\mathrm{amb}}$. After the vapor condenses to liquid at a temperature of $T_{\text {con }}$, it is being subcooled to the ambient temperature by rejecting energy to the ambient surroundings. The differential condensation energy of $\delta m_{\text {con }}$ is then given by

$$
\delta Q_{\text {con }}=\delta m_{\text {con }}\left[h_{g}\left(P_{\text {con }}, T\right)-h_{f}\left(T_{\mathrm{amb}}\right)\right],
$$

where $h_{f}\left(T_{\mathrm{amb}}\right)$ is the refrigerant liquid specific enthalpy at the ambient temperature. 


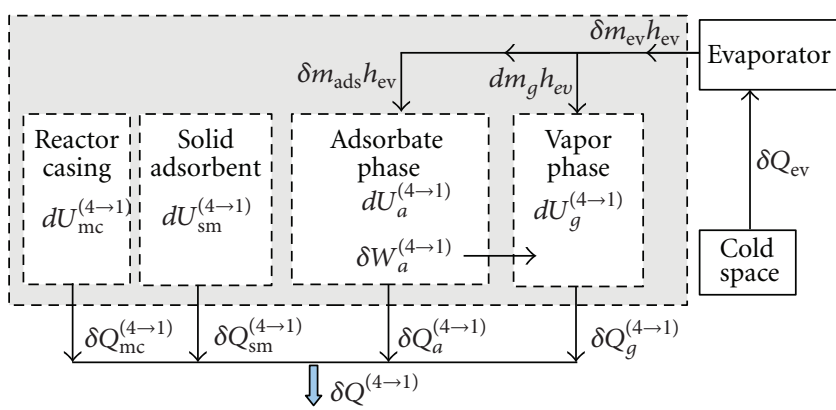

Figure 9: Energy flow diagram for the adsorption reactor during process $4 \rightarrow 1$.

6.6. The Throttling Process. In the throttling process, the refrigerant conserves its total enthalpy. Therefore, the wetness fraction $y$ of the refrigerant after the throttling process is given by

$$
y=1-\frac{h_{f}\left(T_{\mathrm{amb}}\right)-h_{f}\left(T_{\mathrm{ev}}\right)}{L\left(T_{\mathrm{ev}}\right)},
$$

where $h_{f}\left(T_{\text {ev }}\right)$ is the refrigerant saturated liquid specific enthalpy corresponding to the evaporator temperatures. The term $L\left(T_{\mathrm{ev}}\right)$ is the latent energy of the vaporization of the refrigerant at the evaporator temperature. The fraction of liquid that evaporates in this process, $1-y$, causes a selfcooling of the remaining liquid fraction, $y$, and consequently reduces its temperature from the ambient temperature to the evaporator temperature.

6.7. The Evaporator. In the evaporator, cold production takes place by the evaporation of the saturated liquid refrigerant. The differential cooling effect, $\delta Q_{\mathrm{ev}}$, associated with a differential amount of refrigerant liquid, $\delta m_{\mathrm{ev}}$, is calculated from

$$
\delta Q_{\mathrm{ev}}=y \delta m_{\mathrm{ev}} L\left(T_{\mathrm{ev}}\right),
$$

where $\delta m_{\mathrm{ev}}$ is the mass of the refrigerant vapor which is coming from the evaporator and is being adsorbed in the adsorption reactor, (48).

6.8. The System Performance. In general, the efficiency of any cooling system is measured by the coefficient of performance, $(\mathrm{COP})_{R}$, which is a measure of how efficiently the input energy is transformed to a useful output cooling effect. The $(\mathrm{COP})_{R}$ is given by

$$
(\mathrm{COP})_{R}=\frac{Q_{\mathrm{ev}}}{Q_{\mathrm{in}}} .
$$

In this equation, the refrigeration effect $Q_{e v}$ is given by

$$
Q_{\mathrm{ev}}=\int_{4}^{1} \delta Q_{\mathrm{ev}}
$$

and the required input energy to drive the system $Q_{\text {in }}$ is given by

$$
Q_{\text {in }}=\int_{1}^{2} \delta Q^{1 \rightarrow 2}+\int_{2}^{3} \delta Q^{2 \rightarrow 3}
$$
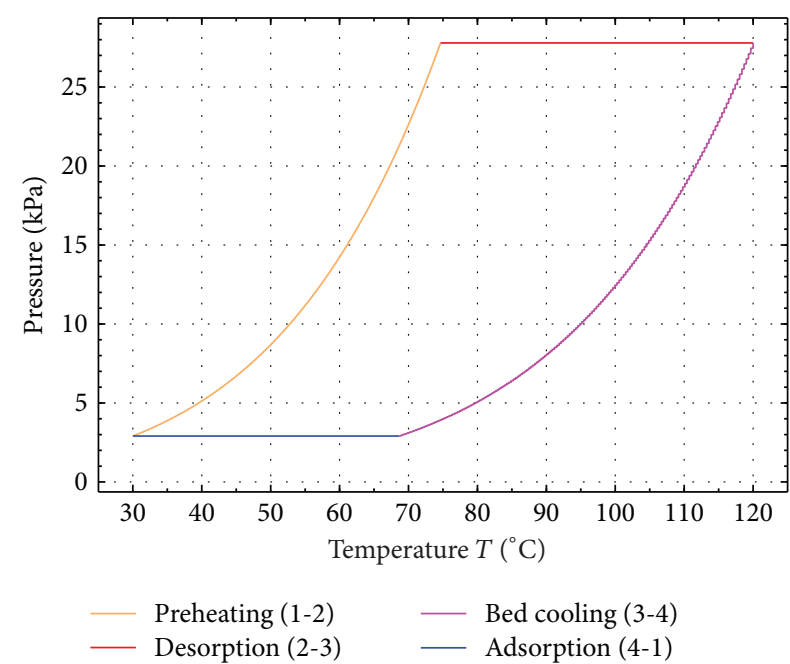

FIGURE 10: Variation of the reactor pressure versus the temperature along the cycle.

The effective refrigerant mass, $M_{\mathrm{eff}}$, is the total mass of the desorbed refrigerant from the adsorption reactor which is circulated through the condenser and the evaporator. This refrigerant mass is responsible for providing the cooling effect inside the evaporator and is given by the following equation:

$$
M_{\mathrm{eff}}=m_{\mathrm{sm}}\left(\mathscr{X}_{\max }^{*}-\mathscr{X}_{\mathrm{min}}^{*}\right)
$$

Another important parameter which is used in the present study is the refrigerant mass utilization efficiency, $\eta_{\mathrm{rmu}}$. This parameter is defined as the ratio between the effective refrigerant mass, $M_{\text {eff }}$, to the total refrigerant mass which is required to charge the system. The refrigerant mass utilization efficiency is defined by the following equation:

$$
\eta_{\mathrm{rmu}}=\frac{M_{\mathrm{eff}}}{m_{\mathrm{sm}} \mathscr{X}_{\mathrm{max}}^{*}}=1-\frac{\mathscr{X}_{\mathrm{min}}^{*}}{\mathscr{X}_{\mathrm{max}}^{*}} .
$$

When the cooling system is used for freezing applications, the total amount of the ice produced from the ACP system per cycle is given by

$$
\begin{array}{r}
m_{\mathrm{ice}}=\frac{\mathrm{Q}_{\mathrm{ev}}}{C_{w}\left(T_{w}-273\right)+L_{f}+C_{\mathrm{ice}}\left(273-T_{\mathrm{ev}}\right)}, \\
T_{\mathrm{ev}} \leq 273 \mathrm{~K},
\end{array}
$$

where $T_{w}$ is the initial water temperature and $C_{w}, C_{\text {ice }}$, and $L_{f}$ are the water specific heat, the ice specific heat, and the latent heat of ice fusion, respectively.

If the cooling system is used as a water chiller, the daily production of chilled water is given by

$$
m_{w}=\frac{Q_{\mathrm{ev}}}{C_{w}\left(T_{w}-T_{\mathrm{ev}}\right)}, \quad T_{\mathrm{ev}} \geq 273 \mathrm{~K} .
$$


TABLE 1: The base line parameters used in the case study.

\begin{tabular}{lccc}
\hline Parameter & Value & Parameter & Value \\
\hline$T_{\text {ev }}$ & $-5^{\circ} \mathrm{C}$ & $T_{\text {con }}$ & $35^{\circ} \mathrm{C}$ \\
$T_{\max }$ & $120^{\circ} \mathrm{C}$ & $T_{\text {amb }}$ & $30^{\circ} \mathrm{C}$ \\
$\rho_{s}$ & $2200 \mathrm{~kg} \cdot \mathrm{m}^{-3}$ & $C_{\text {sm }}$ & $711 \mathrm{~J} / \mathrm{kg} \cdot \mathrm{K}$ \\
$\varepsilon$ & 0.74 & $V_{b}$ & $0.1 \mathrm{~m}^{3}$ \\
\hline
\end{tabular}

\section{The Case Study}

The case investigated in the present study is an ice maker and produces ice at a temperature of $-5^{\circ} \mathrm{C}$. The system operates with activated carbon-methanol as the working pair. The liquid and vapor thermodynamic properties of methanol have been calculated from the methanol equation of state reported by the IUPAC [40]. The base line parameters used in this case study are summarized in Table 1. Moreover, the effect of metallic casing of the adsorption bed is not taken into account in this studied case.

\section{Results and Discussions of the Case Study}

Based on the introduced thermodynamic analysis in Section 6 and the case study described in Section 7, a computer program is developed to solve the mathematical model of the ACP system. An energy balance for the whole system including the bed, the evaporator, and the condenser is performed as a numerical experimentation of the developed computer code. It is found that the total energy input to the cycle, $Q_{\text {add }}=Q^{1 \rightarrow 2}+Q^{2 \rightarrow 3}+Q_{\text {ev }}$, equals $318.634 \mathrm{MJ}$, whereas, the total energy output from the system, $Q_{\text {rej }}=$ $Q^{3 \rightarrow 4}+Q^{4 \rightarrow 1}+Q_{\text {con }}$, equals 318.615 MJ. Therefore, the relative error, $100 \times\left(Q_{\text {add }}-Q_{\text {rej }}\right) / Q_{\text {add }}$, in the calculations is nearly $0.006 \%$ which is an acceptable numerical error and validates the calculation accuracy.

Generally, it is found that the system attains a refrigeration COP of 0.616 with a refrigeration effect produced inside the evaporator estimated to $12.15 \mathrm{MJ}$ per cycle. This cooling effect corresponds to ice production of $27 \mathrm{~kg}$ per cycle at $-5^{\circ} \mathrm{C}$ from water at a source temperature of $25^{\circ} \mathrm{C}$. Therefore, every $1 \mathrm{~kg}$ of activated carbon inside the adsorption reactor produces ice mass of $0.471 \mathrm{~kg}$ per cycle at a temperature of $-5^{\circ} \mathrm{C}$. Figure 10 plots the relation between the adsorption bed pressure and temperature for all of the four cycle processes. The adsorption bed pressure rises from the evaporator pressure at $2.91 \mathrm{kPa}$ to the highest cycle pressure at the condenser, $27.79 \mathrm{kPa}$, during the preheating process. It can be also seen that the adsorbent starts the generation process at a temperature of about $74.65^{\circ} \mathrm{C}$. Then the bed pressure remains steady during the generation process till the maximum cycle temperature, $120^{\circ} \mathrm{C}$, is approached. Figure 11 illustrates the variation of the adsorbate phase concentration ratio with the adsorption bed temperature along the cycle. From this plot, the adsorbate concentration ratio varies between its maximum value of $0.24 \mathrm{~kg} / \mathrm{kg}$ to its minimum value of $0.051 \mathrm{~kg} / \mathrm{kg}$ during the cycle. This corresponds to a maximum and a minimum contents of an adsorbed refrigerant phase

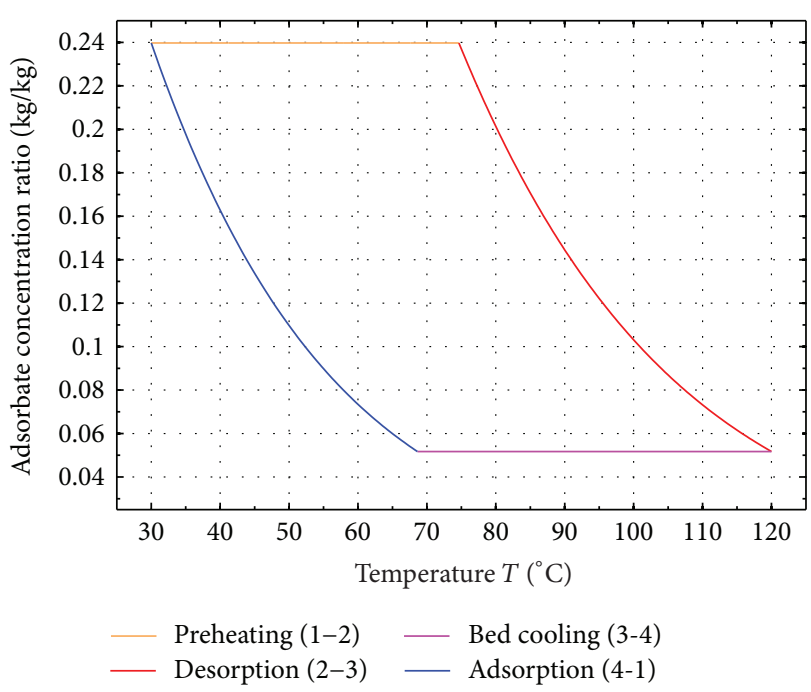

FIGURE 11: Variation of the refrigerant concentration with temperature along the cycle.

mass of $13.76 \mathrm{~kg}$ and $2.97 \mathrm{~kg}$, respectively. As a result, the total refrigerant effective mass which is circulated through the system is $10.79 \mathrm{~kg}$. In other words, the refrigerant mass utilization efficiency is estimated to be $78.43 \%$.

The development of the adsorbate volume fraction with the bed temperature is demonstrated in Figure 12. As noticed from this figure, the adsorbate volume fraction is continuously varying throughout the cycle operation. Slight changes of the adsorbate refrigerant volume fraction are noticed during both of the two isosteric processes. In the isosteric preheating phase, the volume fraction increases with temperature due to the decrease in adsorbed refrigerant density with increasing temperature. It attains its highest cyclic value at the end of this phase, about 0.186 , whereas, the decreasing trend in the adsorbed phase volume fraction during the isosteric cooling process is due to the increase in its density with the decreasing bed temperature. It attains its minimum value at the end of isosteric cooling process, about 0.04 . Figure 13 presents the evolution of the refrigerant desorbed mass from the adsorption reactor during the isobaric process $2 \rightarrow 3$. It is noticed that the rate of the generated refrigerant has its maximum value at the beginning of the desorption process, when the bed temperature reaches the value of the generation temperature. This rate, as depicted in the plot, is continuously decreasing with increasing the bed temperature and it approaches the minimum value at the end of the desorption phase, at the maximum cycle temperature and the minimum concentration. The total desorbed refrigerant vapor mass at the end of this process equals $10.79 \mathrm{~kg}$. Furthermore, the adsorbed refrigerant mass evolution as a function of the adsorption reactor pressure during process $4 \rightarrow 1$ is demonstrated in Figure 14 .

The cumulative sum of the energy added to the adsorption reactor per unit mass of the solid adsorbent is demonstrated in Figure 15 versus the bed temperature. The total amount of the specific energy required to activate the adsorption bed is estimated to $343.33 \mathrm{~kJ} / \mathrm{kg}$ per cycle. A fraction 


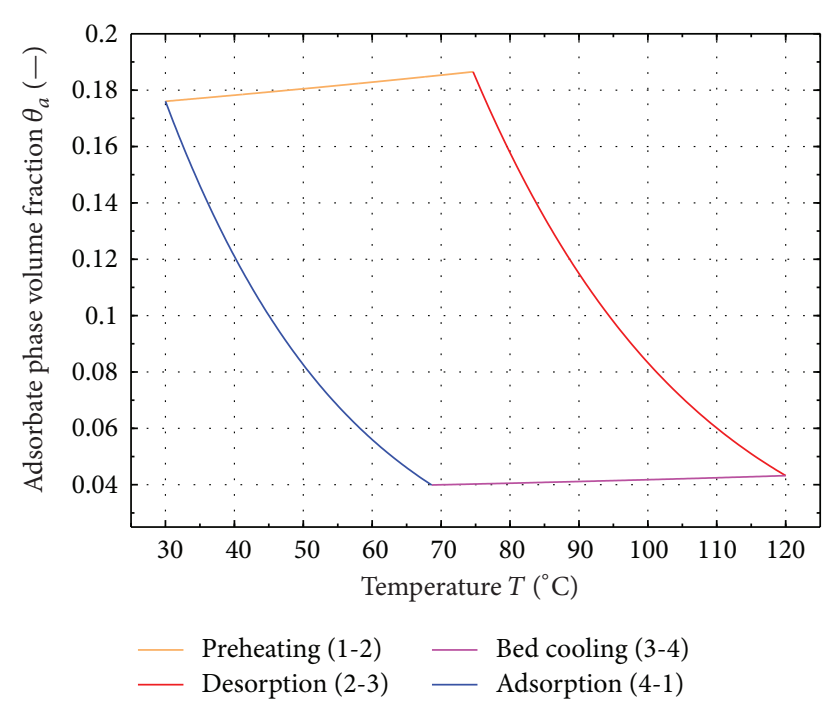

FIGURE 12: Adsorbate refrigerant volume fraction-temperature relation.

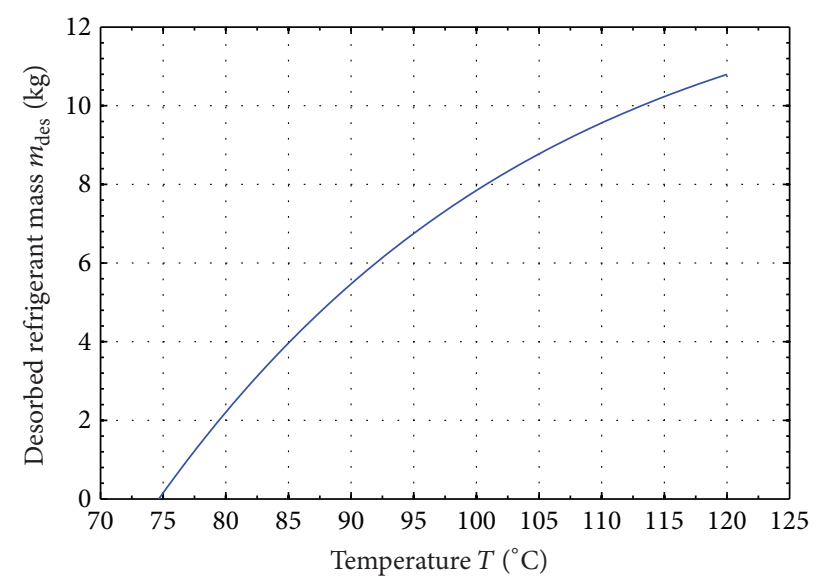

Figure 13: Evolution of the desorbed refrigerant mass during process $2 \rightarrow 3$.

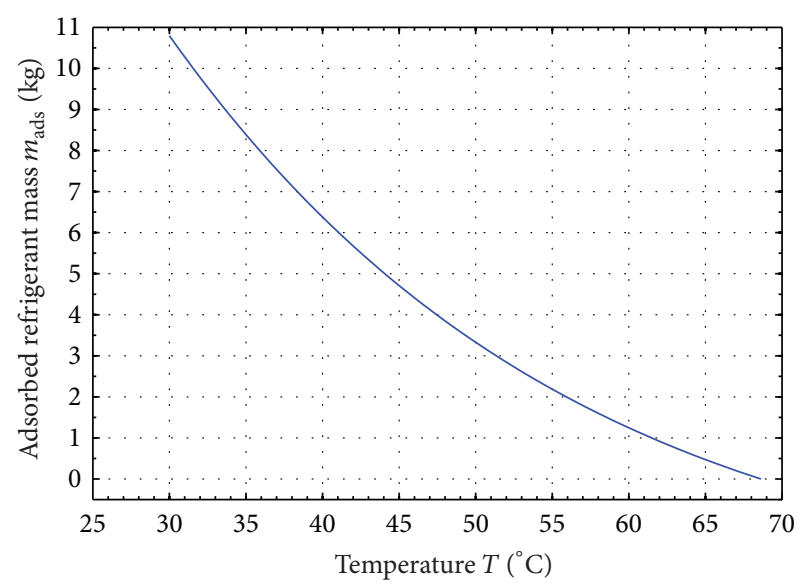

FIGURE 14: Evolution of the adsorbed refrigerant mass during process $4 \rightarrow 1$.

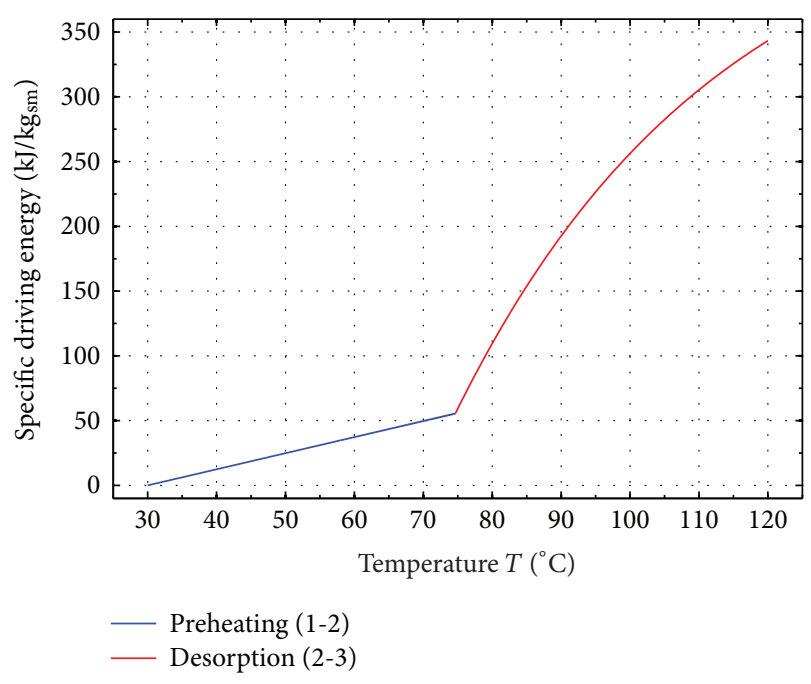

FIGURE 15: Cumulative sum of specific energy added to the adsorption reactor during the bed heating processes.

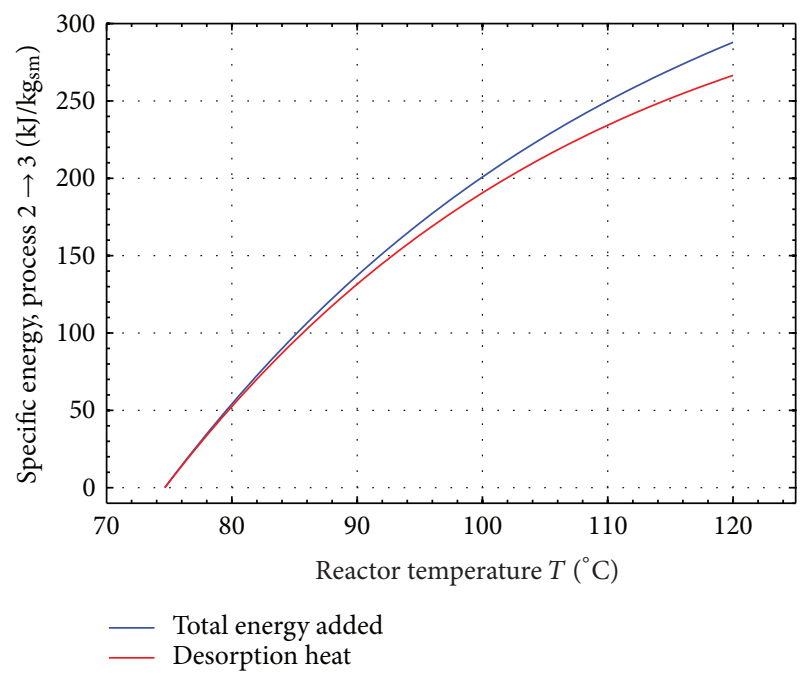

FIGURE 16: The cumulative sum of specific energy added to the bed and the specific isosteric energy during the desorption process.

from this energy, about $16.15 \%$, is needed to bring the reactor up to the generation temperature, whereas, the constant pressure desorption process requires the remaining part of the total energy added, $83.84 \%$. As noticed from the plot in Figure 15, there is a more rapid increase in the temperature during the preheating process than in the desorption process with respect to the specific driving energy. The reason is that all of the energy input to the adsorption bed during the process $1 \rightarrow 2$ is consumed only in the sensible heating of the bed, whereas, in process $2 \rightarrow 3$, a large portion of energy is consumed in the refrigerant generation process. Figure 16 illustrates a comparison of the specific total energy added to the adsorption bed and the specific isosteric desorption energy during the desorption process. As provided in the figure, most of the input energy is being used as activating energy of desorption, about $92.56 \%$. Similarly, the cumulative 


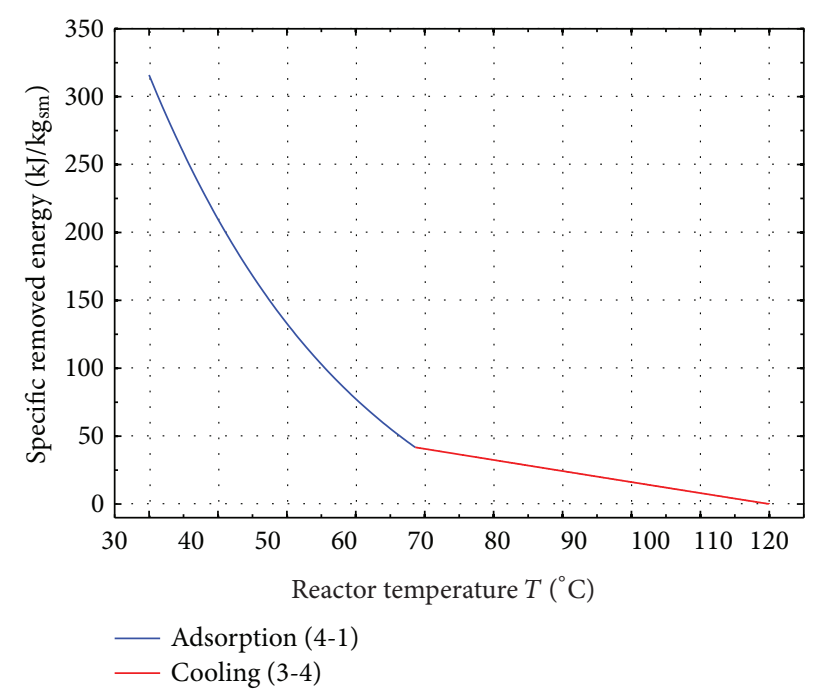

FIGURE 17: Cumulative sum of specific energy rejected from the adsorption reactor during the bed cooling processes.

sum of the specific energy removed from the adsorption reactor during both the isosteric cooling as well as the adsorption process is demonstrated in Figure 17. The total energy removed from the bed during this cooling phase is found to be about $315.97 \mathrm{~kJ} / \mathrm{kg}$ per cycle. About $13.21 \%$ of this energy is lost to the ambient during the constant concentration cooling process in a form of sensible cooling. The remaining larger fraction of this energy is then rejected from the reactor to the surroundings during the adsorption process.

\section{Conclusion}

A simple thermodynamic differential analysis for adsorption refrigeration systems is introduced in the present work. The analysis is based on the energy conservation principle and the D-A adsorption equilibrium model. The case studied is an ice machine working with activated carbon-methanol as the working pair.

\section{Nomenclature}

\footnotetext{
$\mathscr{X}^{*}$ : Adsorbed phase concentration ratio at equilibrium $[\mathrm{kg} / \mathrm{kg}]$

$q_{\mathrm{sh}}$ : Isosteric heat of adsorption or desorption $[\mathrm{J} / \mathrm{kg}]$

$W_{o}:$ The maximum adsorption capacity $\left[\mathrm{m}^{3} / \mathrm{kg}\right]$

$C: \quad$ Specific heat $[\mathrm{J} / \mathrm{kg} \cdot \mathrm{K}]$

D: Constant in Dubinin-Astakhov equation [-]

$h$ : The specific enthalpy $[\mathrm{J} / \mathrm{kg}]$

$L: \quad$ Latent heat of vaporization $[\mathrm{J} / \mathrm{kg}]$

$m: \quad$ Mass [kg]

$n$ : Constant in Dubinin-Astakhov equation [-]

$P: \quad$ Pressure $[\mathrm{Pa}]$

$\mathrm{Q}$ : Thermal energy [J]

T: $\quad$ Temperature [K]
}

$U$ : Total internal energy [J]

$u$ : The specific internal energy $[\mathrm{J} / \mathrm{kg}]$

$V:$ Volume $\left[\mathrm{m}^{3}\right]$

$W:$ Work [J]

$y$ : Wetness fraction $[-]$.

\section{Greek Symbols}

$\eta_{\text {rmu }}:$ The refrigerant mass utilization efficiency [-]

$\rho: \quad$ Density $\left[\mathrm{kg} / \mathrm{m}^{3}\right]$

$\theta^{*}$ : The adsorbate phase volume fraction at equilibrium [-]

$\varepsilon: \quad$ Porosity of the solid adsorbent medium [-].

\section{Superscripts}

$1 \rightarrow 2$ : The isosteric preheating process

$2 \rightarrow 3$ : The isobaric desorption process

$3 \rightarrow 4$ : The isosteric cooling process

$4 \rightarrow 1$ : The adsorption process.

\section{Subscripts}

a: Adsorbate phase

ads: Adsorption

amb: Ambient or atmospheric

$b$ : $\quad$ Bed

con: Condenser or condensation

des: Desorption

eff: Effective

ev: Evaporator

$f: \quad$ Fluid or liquid

$g$ : Gas or vapor phase

gen: Generation

max: Maximum

mc: Metallic shell

min: Minimum

$p$ : Particle

s: $\quad$ Solid

sat: Saturation

sh: Heat of adsorption/desorption

sm: Solid or porous media.

\section{Abbreviations}

ACP: Adsorption cold production

COP: Coefficient of performance [-]

TDCP: Thermally driven cold production

VCR: Vapor compression refrigeration.

\section{References}

[1] F. X. Diebold and R. S. Mariano, "Comparing predictive accuracy," Journal of Business and Economic Statistics, vol. 13, pp. 253-263, 1995.

[2] H. Z. Hassan and A. A. Mohamad, "A review on solar cold production through absorption technology," Renewable \& Sustainable Energy Reviews, vol. 16, no. 7, pp. 5331-5348, 2012.

[3] L. W. Wang, R. Z. Wang, and R. G. Oliveira, "A review on adsorption working pairs for refrigeration," Renewable and Sustainable Energy Reviews, vol. 13, no. 3, pp. 518-534, 2009. 
[4] H. Z. Hassan, A. Mohamad, and R. Bennacer, "Simulation of an adsorption solar cooling system," Energy, vol. 36, no. 1, pp. 530-537, 2011.

[5] F. Meunier and N. Douss, "Performance of adsorption heat pumps. Active carbon-methanol and zeolite-water pairs," ASHRAE Transactions, vol. 2, pp. 267-274, 1990.

[6] R. Z. Wang, J. P. Jia, Y. H. Zhu et al., "Study on a new solid absorption refrigeration pair: active carbon fiber-methanol," Journal of Solar Energy Engineering, Transactions of the ASME, vol. 119, no. 3, pp. 214-218, 1997.

[7] B. B. Saha, I. I. El-Sharkawy, A. Chakraborty, and S. Koyama, "Study on an activated carbon fiber-ethanol adsorption chiller-part II-performance evaluation," International Journal of Refrigeration, vol. 30, no. 1, pp. 96-102, 2007.

[8] M. Louajari, A. Mimet, and A. Ouammi, "Study of the effect of finned tube adsorber on the performance of solar driven adsorption cooling machine using activated carbon-ammonia pair," Applied Energy, vol. 88, no. 3, pp. 690-698, 2011.

[9] D. C. Wang and J. P. Zhang, "Design and performance prediction of an adsorption heat pump with multi-cooling tubes," Energy Conversion and Management, vol. 50, no. 5, pp. 1157-1162, 2009.

[10] E. E. Anyanwu and N. V. Ogueke, "Thermodynamic design procedure for solid adsorption solar refrigerator," Renewable Energy, vol. 30, no. 1, pp. 81-96, 2005.

[11] B. Choudhury, P. K. Chatterjee, and J. P. Sarkar, "Review paper on solar-powered air-conditioning through adsorption route," Renewable and Sustainable Energy Reviews, vol. 14, no. 8, pp. 2189-2195, 2010.

[12] D. C. Wang, Y. H. Li, D. Li, Y. Z. Xia, and J. P. Zhang, "A review on adsorption refrigeration technology and adsorption deterioration in physical adsorption systems," Renewable and Sustainable Energy Reviews, vol. 14, no. 1, pp. 344-353, 2010.

[13] O. S. Headley, A. F. Kothdiwala, and I. A. McDoom, "Charcoalmethanol adsorption refrigerator powered by a compound parabolic concentrating solar collector," Solar Energy, vol. 53, no. 2, pp. 191-197, 1994.

[14] M. I. González and L. R. Rodríguez, "Solar-powered adsorption chiller with CPC collection system: collector design and experimental results," in Proceedings of ISES World Congress, vol. 1, pp. 916-920, 2007.

[15] M. I. González and L. R. Rodríguez, "Solar powered adsorption refrigerator with CPC collection system: collector design and experimental test," Energy Conversion and Management, vol. 48, no. 9, pp. 2587-2594, 2007.

[16] C. Hildbrand, P. Dind, M. Pons, and F. Buchter, "A new solar powered adsorption refrigerator with high performance," Solar Energy, vol. 77, no. 3, pp. 311-318, 2004.

[17] M. Li, R. Z. Wang, Y. X. Xu, J. Y. Wu, and A. O. Dieng, "Experimental study on dynamic performance analysis of a flat-plate solar solid-adsorption refrigeration for ice maker," Renewable Energy, vol. 27, no. 2, pp. 211-221, 2002.

[18] M. Li and R. Z. Wang, "A study of the effects of collector and environment parameters on the performance of a solar powered solid adsorption refrigerator," Renewable Energy, vol. 27, no. 3, pp. 369-382, 2002.

[19] K. C. A. Alam, B. B. Saha, A. Akisawa, and T. Kashiwagi, "Optimization of a solar driven adsorption refrigeration system," Energy Conversion and Management, vol. 42, no. 6, pp. 741-753, 2001.
[20] N. V. Ogueke and E. E. Anyanwu, "Design improvements for a collector/generator/adsorber of a solid adsorption solar refrigerator," Renewable Energy, vol. 33, no. 11, pp. 2428-2440, 2008.

[21] A. El Fadar, A. Mimet, A. Azzabakh, M. Pérez-García, and J. Castaing, "Study of a new solar adsorption refrigerator powered by a parabolic trough collector," Applied Thermal Engineering, vol. 29, no. 5-6, pp. 1267-1270, 2009.

[22] J. J. Guilleminot, F. Meunier, and B. Mischler, "Étude de cycles intermittents à adsorption solide pour la réfrigération solaire," Revue de Physique Appliquée, vol. 15, no. 3, pp. 441-452, 1980.

[23] R. E. Critoph, "Performance limitations of adsorption cycles for solar cooling," Solar Energy, vol. 41, no. 1, pp. 21-31, 1988.

[24] L. Luo and M. Feidt, "Thermodynamics of adsorption cycles: a theoretical study," Heat Transfer Engineering, vol. 13, no. 4, pp. 19-31, 1992.

[25] F. Mhiri and S. El Golli, "Etude d'un refrigerateur solaire a adsorption solide avec le couple charbon actif-methanol," Revue Generate de Thermique, vol. 35, no. 412, pp. 269-277, 1996.

[26] Y. Teng, R. Z. Wang, and J. Y. Wu, "Study of the fundamentals of adsorption systems," Applied Thermal Engineering, vol. 17, no. 4, pp. 327-338, 1997.

[27] H. Z. Hassan, A. A. Mohamad, and H. A. Al-Ansary, "Development of a continuously operating solar-driven adsorption cooling system: thermodynamic analysis and parametric study," Applied Thermal Engineering, vol. 48, pp. 332-341, 2012.

[28] J. Rouquerol, D. Avnir, C. W. Fairbridge et al., "Recommendations for the characterization of porous solids," Pure and Applied Chemistry, vol. 66, pp. 1739-1758, 1994.

[29] J. Rouqucrol, F. Rodriguez-Rcinoso, and K. S. W. Sing, "Characterization of porous solids-III. studies in surface science and catalysis," in Proceedings of the IUPAC Symposium (COPS Ill), pp. 9-12, Marseille, France, 1993.

[30] H. Marsh and F. Rodríguez-Reinoso, Activated Carbon, Elsevier, Boston, Mass, USA, 1st edition, 2006.

[31] R. C. Bansal and M. Goyal, Activated Carbon Adsorption, Taylor \& Francis, Bocaraton, Fla, USA, 2005.

[32] D. D. Duong, Adsorption Analysis: Equilibria and Kinetics, Series on Chemical Engineering, vol. 2, Imperial College Press, London, UK, 1998.

[33] D. M. Ruthven, S. Farooq, and K. S. Knaebel, Pressure Swing Adsorption, John Wiley \& Sons, New York, NY, USA, 1994.

[34] M. M. Dubinin and V. A. Astakhov, "Development of the concepts of volume filling of micropores in the adsorption of gases and vapors by microporous adsorbents-Communication 2. General bases of the theory of adsorption of gases and vapors on zeolites," Bulletin of the Academy of Sciences of the USSR Division of Chemical Science, vol. 20, no. 1, pp. 8-12, 1971.

[35] M. M. Dubinin and V. A. Astakhov, "Description of adsorption equilibria of vapors on zeolites over wide eanges of temperature and pressure," Advances in Chemistry Series, vol. 102, pp. 69-85, 1971.

[36] M. M. Dubinin, "Physical adsorption of gases and vapors in micropores," Progress in Surface and Membrane Science, vol. 9, pp. 1-70, 1975.

[37] B. B. Saha, A. Akisawa, and T. Kashiwagi, "Solar/waste heat driven two-stage adsorption chiller: the prototype," Renewable Energy, vol. 23, no. 1, pp. 93-101, 2001.

[38] Y. A. Cengel and M. A. Boles, Thermodynamics: An Engineering Approach, McGraw-Hill, 7th edition, 2011. 
[39] A. Bejan, Advanced Engineering Thermodynamics, John Wiley \& Sons, 3rd edition, 2006.

[40] K. M. de Reuck, Methanol, International Thermodynamic Tables of the Uid State, vol. 12, Blackwell Science, 1993. 

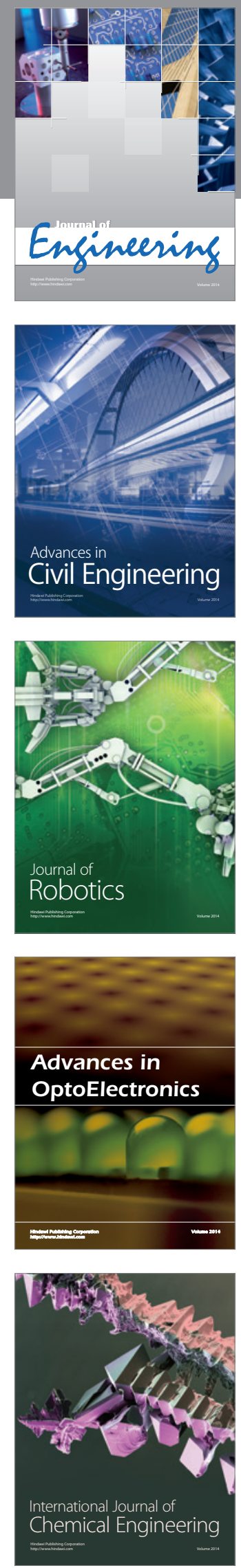

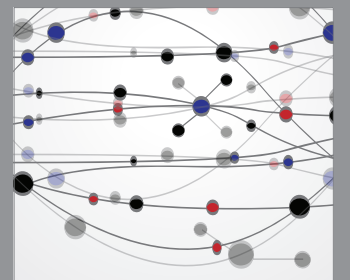

The Scientific World Journal
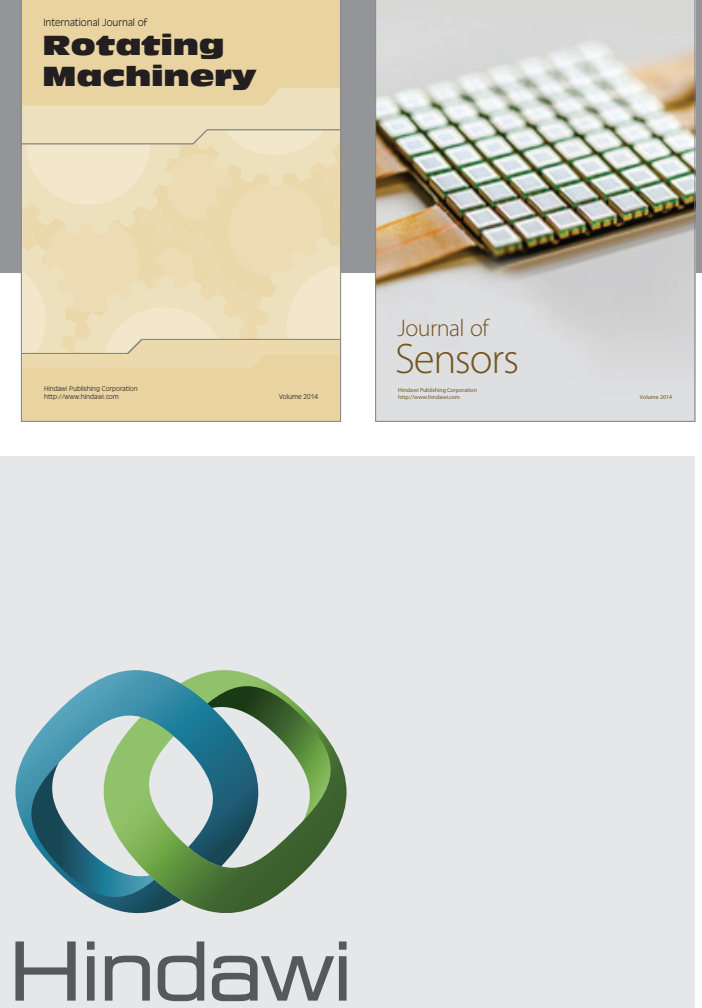

Submit your manuscripts at http://www.hindawi.com
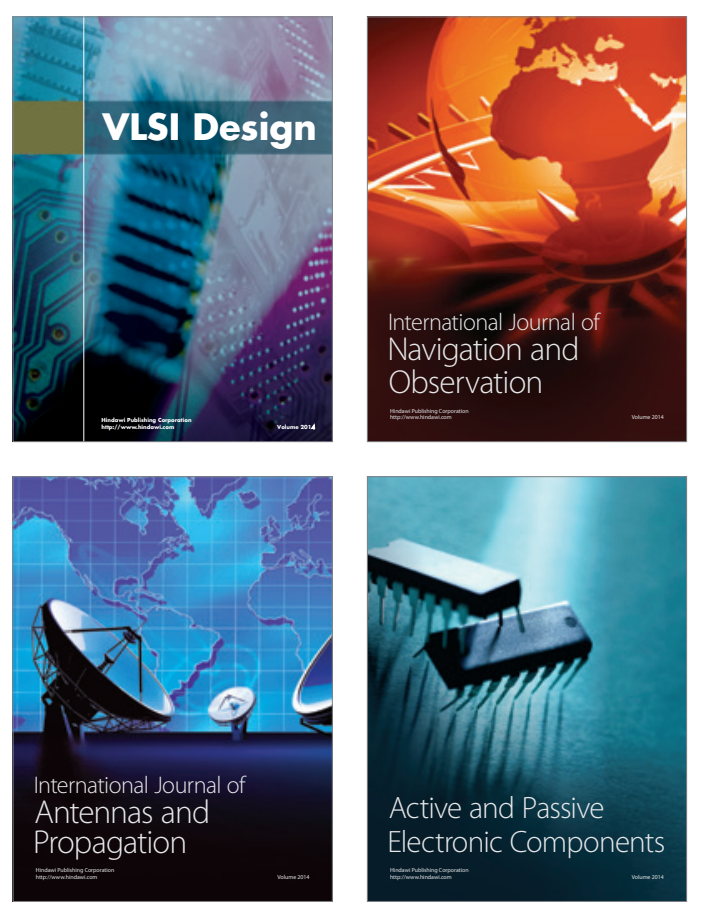
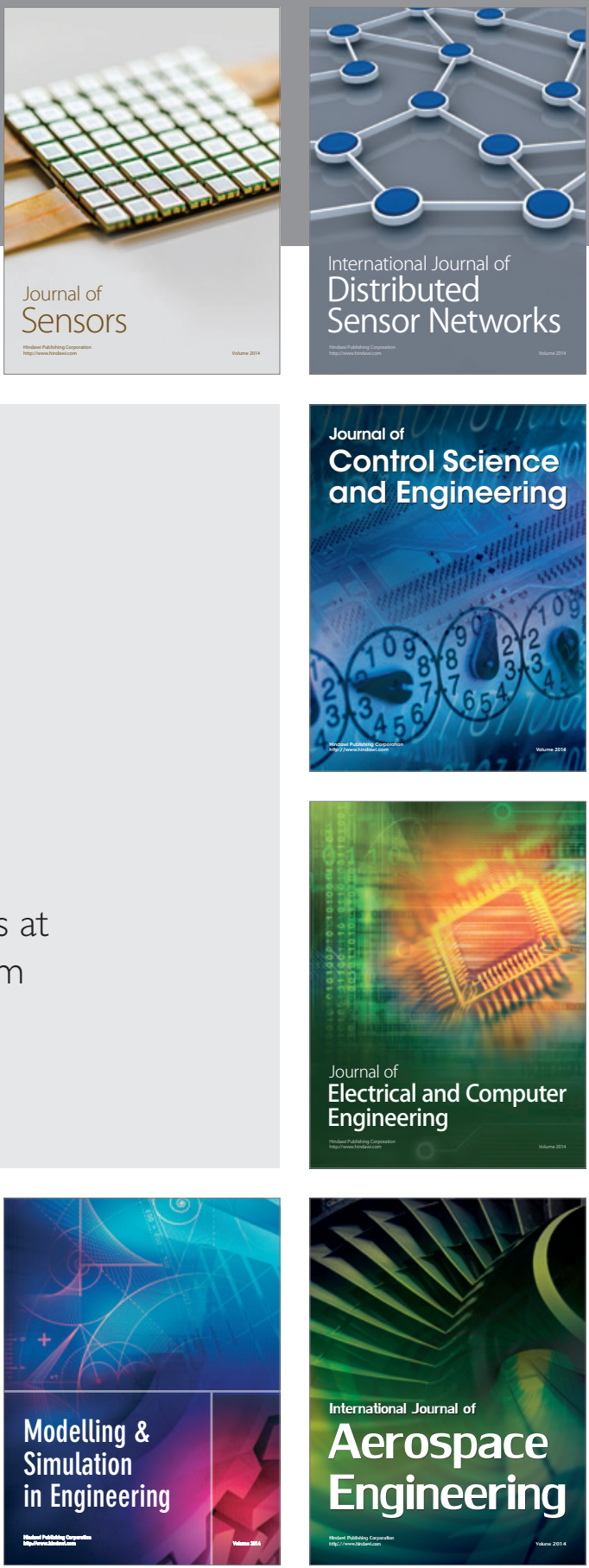

Journal of

Control Science

and Engineering
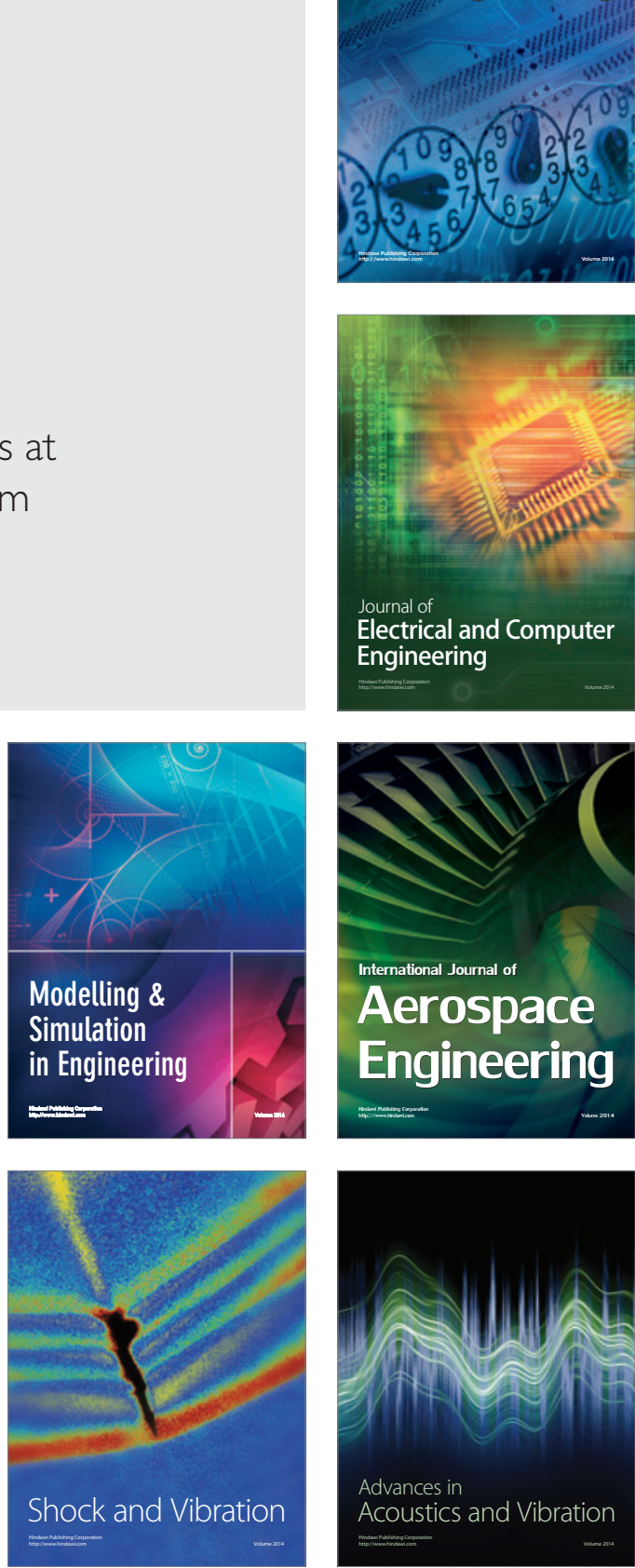